\title{
Role of saline infusion sonography in evaluation of abnormal uterine bleeding
}

\author{
Neerja Gupta1, Geeta Singh ${ }^{1 *}$, Bharti Jain², Satakshi Garg1
}

\begin{abstract}
${ }^{1}$ Department of Obstetrics and Gynecology, ${ }^{2}$ Department of Radiodiagnosis, Muzaffarnagar Medical College, Muzaffarnagar, Uttar Pradesh, India
\end{abstract}

Received: 12 January 2018

Accepted: 10 February 2018

*Correspondence:

Dr. Geeta Singh,

E-mail: geetasingh197@gmail.com

Copyright: () the author(s), publisher and licensee Medip Academy. This is an open-access article distributed under the terms of the Creative Commons Attribution Non-Commercial License, which permits unrestricted non-commercial use, distribution, and reproduction in any medium, provided the original work is properly cited.

\begin{abstract}
Background: Abnormal uterine bleeding (AUB) is one of the most common reasons for women seeking gynaecological advice. The objective of this study was to determine the accuracy of Transvaginal sonography (TVS) and Saline Infusion Sonography (SIS) in evaluation of Abnormal Uterine Bleeding (AUB) and to compare the diagnostic accuracy after hysterectomy.

Methods: Prospective, comparative study of TVS and SIS in evaluation of AUB in patients who are being subjected to hysterectomy with uterus of less than 12 weeks.

Results: 100 patients were included in the study. 98\% were of 30-50 years. Heavy menstrual bleeding was the commonest symptom (52\%) and most common finding was fibroid, and Polyp followed by abnormal endometrium. The overall sensitivity and specificity when correlated with operative and HPE were $66 \%$ and $88 \%$ respectively for TVS and $82 \%$ and $95 \%$ for SIS respectively. The false positive and false negative rates were more in TVS compared to SIS. Commonest histopathology was intramural fibroid in $42 \%$ followed by sub mucus myoma in $21 \%$, polyp $18 \%$ and endometrial hyperplasia $10 \%$.

Conclusions: SIS is a simple highly sensitive and specific technique to detect intra uterine pathology in the evaluation of AUB when TVS findings are inconclusive.
\end{abstract}

Keywords: DH (Diagnostic Hysteroscopy), HPE (Histopathology), HMB (Heavy menstrual bleeding), SIS, TVS

\section{INTRODUCTION}

Abnormal uterine bleeding (AUB) is one of the most common reasons for women seeking gynaecological advice. It accounts for $15 \%$ of office visits and about $25 \%$ of gynaecological surgeries. ${ }^{1}$ Other than dysfunctional uterine bleeding (DUB), intrauterine abnormalities are the leading cause of AUB.

The most common anatomical causes of AUB in $40 \%$ pre-menopausal women are sub-mucosal fibroids, endometrial polyps and endometrial hyperplasia. ${ }^{1,2}$ The most frequent procedure performed on women with abnormal uterine bleeding is transvaginal ultrasound. For many years the most common accepted approach for the management of abnormal uterine bleeding has been the TV scan followed by therapeutic hysteroscopy combined with a histological examination of the obtained specimen.

Trans-vaginal sonography (TVS) is used as an initial investigation because it is easy, rapid and cost effective, but it is unable to differentiate intrauterine pathology with complete certainty. ${ }^{3}$

The gold standard for diagnosis of intrauterine abnormalities is diagnostic hysteroscopy combined with a 
histological examination of endometrial aspiration or biopsy. Hysteroscopy is invasive, reasonably expensive, time consuming, and involves anaesthesia. Hysteroscopy is also associated with risks like uterine perforation and ascending genitourinary infection. ${ }^{4}$

Saline infusion sonography (SIS) in comparison to hysteroscopy is less invasive, cheaper, and does not require anaesthesia. SIS reliably evaluates uterine contour, adhesions, and focal pathologies. Furthermore, in SIS, after distending the cavity with saline, there is clear visualization of the inner surface of both sides of the endometrium. ${ }^{5}$ Focal and diffuse abnormalities can be distinguished, and in most cases an endometrial polyp can be differentiated from the submucous fibroid based on the imaging characteristics. The polyps are typically round in shape, smooth in outline, and are generally echogenic, compared to the endometrium or are isoechoic to it. The underlying endometrial-myometrial interface is preserved.

The presence of a vascular pedicle has a positive predictive value of up to $81.3 \%$. Fibroids are more homogeneous, hypoechoic, and there is a loss of endometrial-myometrial interface. The percentage of the intracavitary portions of the submucous fibroids can be assessed by SIS. In addition, the submucous fibroids can be differentiated from the intramural fibroids that are distorting the cavity. Thus, by distending the inner walls of the endometrium, focal and diffuse lesions can be identified, along with the location and size of the pathology, with reasonable accuracy. ${ }^{6-9}$

SIS is easily accepted by most patients as an outpatient procedure. Complications are rare with SIS. The patient may experience anxiety, discomfort, and mild lower abdominal cramps during balloon inflation and instillation of saline. ${ }^{10}$ However, the symptoms abate soon after the end of the procedure.

Vaginal spotting may also occur for one or two days after the procedure. Only $1 \%$ to $2 \%$ infection was reported, mostly as endometritis. ${ }^{11,12}$ The procedure is usually welltolerated. The purpose of the study was to assess whether saline infusion sono-hysterography (SIS) can replace diagnostic hysteroscopy (DH) for the diagnosis of endometrial pathology in patients with abnormal uterine bleeding.

\section{METHODS}

This study was done at Department of Obstetrics and Gynaecology of tertiary care centre of Uttar Pradesh, India from January 2015 to July 2016 after obtaining permission from the institutional ethics committee.

In this prospective study, 100 pre and peri menopausal patients with abnormal uterine bleeding were at randomly included in the study. Only those women having AUB with uterine size less than 12 weeks and having no other significant medical history were included in the study. Patients having acute pelvic infection, pregnancy, endometrial carcinoma (diagnosed/suspected) were excluded from the analysis.

Procedure of this study detailed history was taken, and relevant examination was done. TVS and SIS were performed with the help of $7.5 \mathrm{MHz}$ vaginal probe a day before surgery. After performing baseline ultrasound, the uterus was imaged in the sagittal plane, which includes the entire length of cervical canal. As per the TVS normal endometrium and uterine cavity were defined by a centrally placed echo-dense line within the uterus and a homogeneous endometrial lining with distinct margins to the myometrium.

Thickness of endometrium was measured from basalis to basalis in the longitudinal plane. Both wall of the endometrium individually and added together was used for measuring endometrial thickness on SIS. SIS was performed just after TVS without scheduling for the phase of the menstrual cycle.

For SIS 8 number Foley's catheter was introduced into uterine cavity, bulb inflated with $3 \mathrm{ml}$ of normal saline and mild traction given so as to place the bulb at the internal OS. $50 \mathrm{ml}$ of syringe contain normal saline was attached to the catheter. Vaginal probe was introduced, and sterile saline was infused until the distension of uterine cavity was adequate to see any lesion or till pain appears and findings were noted. 15 to $30 \mathrm{ml}$ saline was used in the majority cases.

Macroscopic inspection of hysterectomy specimen and histological examination were compared with the findings at SIS and TVS. Investigators involved in examination of these specimens were not aware about the findings of each other.

\section{Statistics analysis}

The data was reported in the form of frequency, percentages. Sensitivity, specificity, positive predictive value, negative predictive values were calculated. Diagnostic accuracy test (DA test) was used to assess the accuracy for this method and the test was statistically significant $(\mathrm{P}<0.05)$. Open epi software and SPSS version 17 and Medcale was used for data analysis.

\section{RESULTS}

Majority of patient (92\%) were between ages 31-50 years. Maximum $52 \%$ of patients were having uterine size between bulky to 6 weeks. HMB, meno-metrorrhagia and polymenorrhea were most common complain on presentation (Table 1).

As per histopathology report among the patients with abnormal histopathology, most common types were 
Intramural myoma (50\%), Polyp (18\%) and submucous fibroid (14\%) (Table 2).

Table 1: Demographical and clinical parameters of the subjects included in the study.

\begin{tabular}{|l|l|}
\hline Parameters & Subjects $(\mathbf{n = 1 0 0})$ \\
\hline Age (in years) & \\
\hline $31-40$ & 41 \\
\hline $41-50$ & 51 \\
\hline $51-60$ & 8 \\
\hline Uterine size & 14 \\
\hline Normal & 52 \\
\hline Bulky to 6 weeks & 20 \\
\hline $6-8$ weeks & 8 \\
\hline $8-10$ weeks & 6 \\
\hline $10-12$ weeks & \\
\hline Parity & 2 \\
\hline Primi parous & 31 \\
\hline Multiparous (<4) & 67 \\
\hline Grand multiparous (>4) & \\
\hline Symptoms & 64 \\
\hline Heavy menstrual bleeding (HMB) & 10 \\
\hline Meno-metrorrhagia & 10 \\
\hline Polymenorrhoea & 2 \\
\hline Metrorrhagia & 2 \\
\hline Dysmenorrhoea & 12 \\
\hline Continuous bleeding & \\
\hline Values in parenthesis are percentages & \\
\hline
\end{tabular}

Table 2: Findings of TVS and SIS.

\begin{tabular}{|lll|}
\hline Findings & TVS & SIS \\
No. $(\%)$ & No. $(\%)$ \\
\hline Intramural fibroid uterus & $48(48)$ & $50(50)$ \\
\hline Submucous fibroid & $18(18)$ & $14(14)$ \\
\hline Polyps & $16(16)$ & $18(18)$ \\
\hline Myohyperplasia/adenomyosis & $10(10)$ & $10(10)$ \\
\hline Thickened endometrium & $06(6)$ & $05(5)$ \\
\hline Normal endometrium & $02(2)$ & $02(2)$ \\
\hline $\begin{array}{l}\text { Endometrial cavity could not } \\
\text { be distended }\end{array}$ & - & $01(1)$ \\
\hline Total (n) & 100 & 100 \\
\hline
\end{tabular}

Table 3 shows comparison of TVS and SIS findings with HPE reports. It shows that, 2 cases of intramural myoma were falsely diagnosed as sub mucosal myoma, out of 18 cases of polyp, 2 cases were missed, and one case of abnormal endometrium was missed on TVS.

Comparison of TVS and SIS efficacy is mentioned in Table 4, TVS findings has overall sensitivity of 71.43 , specificity 67.7, PPV 54.35, NPV 81.48, DA 69, LR positive 2.22 and negative 0.42 while SIS has sensitivity of 92.86 , specificity 89.65 , PPV 86.67 , NPV 94.54, DA 91, LR positive 8.98 and negative $0.07(\mathrm{P}<0.05)$. For submucousal fibroid, Sensitivity was 61.54 and specificity $97.67 \%$. For polyp false positive were 3, false negative was 5, sensitivity $70 \%$ and specificity $95.35 \%$.
Table 3: Comparison of TVS and SIS findings with intra operative hysterectomy and HPE.

\begin{tabular}{|llll|}
\hline & TVS & SIS & HIPE \\
\hline Intramural fibroid uterus & $48(48)$ & $50(50)$ & 50 \\
\hline Submucous fibroid & $18(18)$ & $14(14)$ & 14 \\
\hline Polyps & $16(16)$ & $18(18)$ & 18 \\
\hline $\begin{array}{l}\text { Myohyperplasia/ } \\
\text { adenomyosis }\end{array}$ & $06(06)$ & $6(6)$ & 6 \\
\hline $\begin{array}{l}\text { Abnormal endometrium } \\
\text { Normal endometrium }\end{array}$ & $04(4)$ & $05(5)$ & 5 \\
\hline
\end{tabular}

Table 4: Comparison between TVS and SIS.

\begin{tabular}{|c|c|c|}
\hline Test & TVS & SIS \\
\hline Sensitivity & $\begin{array}{l}71.43 \\
(54.94 \% \text { to } 83.67 \%)\end{array}$ & $\begin{array}{l}92.86 \\
(80.99 \text { to } 97.54)\end{array}$ \\
\hline Specificity & $\begin{array}{l}67.7 \\
(55.61 \text { to } 77.79)\end{array}$ & $\begin{array}{l}89.65 \\
(73.82 \text { to } 93.74)\end{array}$ \\
\hline PPV & $\begin{array}{l}54.35 \\
(40.18 \text { to } 67.84)\end{array}$ & $\begin{array}{l}86.67 \\
(73.82 \text { to } 93.74)\end{array}$ \\
\hline NPV & $\begin{array}{l}81.48 \\
(69.16 \text { to } 89.61)\end{array}$ & $\begin{array}{l}94.54 \\
(85.14 \text { to } 98.12)\end{array}$ \\
\hline DA & $\begin{array}{l}69 \\
(59.94 \text { to } 78.06)\end{array}$ & $\begin{array}{l}91 * \\
(85.44 \text { to } 96.61)\end{array}$ \\
\hline \multicolumn{3}{|c|}{ Likelihood ratio } \\
\hline Positive & $\begin{array}{l}2.22 \\
(1.47 \text { to } 3.33)\end{array}$ & $\begin{array}{l}8.98 \\
(4.19 \text { to } 19.24)\end{array}$ \\
\hline Negative & $\begin{array}{l}0.42 \\
(0.25 \text { to } 0.72)\end{array}$ & $\begin{array}{l}0.07 \\
(0.03-0.24)\end{array}$ \\
\hline
\end{tabular}

${ }^{*} \mathrm{p}=0.002$ Note Sensitivity, specificity, positive predictive value (PPV), negative predictive value (NPV), and diagnostic accuracy (DA) data are percentages. All numbers in parentheses are $95 \%$ CIs.

Table 5 shows comparison of SIS findings with HPE reports. For intramural myoma and sub mucosal myoma SIS findings were correlated well with intra operative findings and HPE reports with sensitivity of $100 \%$ and specificity of $100 \%$, and for polyp showed sensitivity of $100 \%$ and specificity of $97.85 \%$ while sensitivity and specificity of TVS for submucous fibroid was 61.54 and 96.67 and for polyp was 70 and 95.35 respectively. Thus, it is clear from Table 4 and Table 5 SIS has higher sensitivity and specificity $(\mathrm{P}<0.05)$ in comparison to TVS.

Table 6 shows diagnostic performance of TVS and SIS. The SIS was more sensitive and specific as compared to TVS alone. The positive predictive value of SIS was $96.08 \%$ as compared to $95.56 \%$ for TVS. The diagnostic accuracy of SIS (98\%) was better than that of TVS $(92 \%)$.

\section{DISCUSSION}

AUB is an important and common problem encountered in Gynecology practice. Endometrial and uterine abnormalities such as leiomyoma, polyps and hyperplasia are more common than was previously thought. Though 
TVS is the first imaging modality of choice for the evaluation of endometrial cavity in AUB of less than 12 weeks size uterus, it has limitations in detecting small lesions, location of myoma and in differentiating diffuse and focal lesion. Hysteroscopy has been considered as the gold standard, but it is expensive, invasive and does not contribute in the evaluation of myometrial or ovarian pathology.

Table 5: Comparison of TVS and SIS findings with intra operative hysterectomy and HPE.

\begin{tabular}{|c|c|c|c|c|c|c|}
\hline \multirow{2}{*}{$\begin{array}{l}\text { Diagnosis } \\
\text { Test Performance }\end{array}$} & \multicolumn{2}{|c|}{$\begin{array}{l}\text { Endometrial Hyperplasia } \\
\text { (abnormal Endometrium) }\end{array}$} & \multicolumn{2}{|c|}{ Endometrial Polyp } & \multicolumn{2}{|c|}{ Submucous myoma } \\
\hline & TVS & SIS & TVS & SIS & TVS & SIS \\
\hline Sensitivity & $\begin{array}{l}81.25 \\
(56.99-93.40)\end{array}$ & $\begin{array}{l}93.75 \\
(71.75-98.88)\end{array}$ & $\begin{array}{l}70 \\
(39.67-89.22)\end{array}$ & $\begin{array}{l}90 \\
(59.58-98.21)\end{array}$ & $\begin{array}{l}61.54 \\
(35.52-82.29)\end{array}$ & $\begin{array}{l}100 \\
(77.19 \text { to } 100\end{array}$ \\
\hline Specificity & $\begin{array}{l}73.68 \\
(61.02-83.35)\end{array}$ & $\begin{array}{l}91.23 \\
(81.05-96.19)\end{array}$ & $\begin{array}{l}95.35 \\
(84.54-98.71)\end{array}$ & $\begin{array}{l}98.11 \\
(90.05-99.66)\end{array}$ & $\begin{array}{l}97.67 \\
(87.94-99.58)\end{array}$ & $\begin{array}{l}100 \\
(93.12-100)\end{array}$ \\
\hline PPV & $\begin{array}{l}46.43 \\
(29.53-64.18)\end{array}$ & $\begin{array}{l}75 \\
(53.12-88.81)\end{array}$ & $\begin{array}{l}77.78 \\
(45.25-93.67)\end{array}$ & $\begin{array}{l}90 \\
(59.58-98.21)\end{array}$ & $\begin{array}{l}88.89 \\
(56.50-98.01)\end{array}$ & $\begin{array}{l}100 \\
(77.19-100)\end{array}$ \\
\hline NPV & $\begin{array}{l}93.33 \\
(82.14-97.70)\end{array}$ & $\begin{array}{l}98.11 \\
(90.05-99.66)\end{array}$ & $\begin{array}{l}93.18 \\
(81.77-97.65)\end{array}$ & $\begin{array}{l}98.11 \\
(90.05-99.66)\end{array}$ & $\begin{array}{l}89.36 \\
(77.40-95.36)\end{array}$ & $\begin{array}{l}100 \\
(93.12-100)\end{array}$ \\
\hline DA & $\begin{array}{l}75.34 \\
(65.45-85.23)\end{array}$ & $\begin{array}{l}91.78 * \\
(85.48-98.08)\end{array}$ & $\begin{array}{l}91.57 \\
(82.70-98.44)\end{array}$ & $\begin{array}{l}96.83 \\
(92.50-101.15)\end{array}$ & $\begin{array}{l}89.36 \\
(81.18-97.39)\end{array}$ & $100.00 * *$ \\
\hline \multirow{2}{*}{$\begin{array}{l}\text { Likelihood Ratio } \\
\text { Positive } \\
\text { Negative }\end{array}$} & $\begin{array}{l}3.09 \\
(1.88 .-5.06)\end{array}$ & $\begin{array}{l}10.69 \\
(4.58-24.92)\end{array}$ & $\begin{array}{l}15.05 \\
(3.66-61.82)\end{array}$ & $\begin{array}{l}47.7 \\
(6.77-336.05)\end{array}$ & $\begin{array}{l}26.46 \\
(3.64-192.45)\end{array}$ & $\mathrm{CO}$ \\
\hline & $\begin{array}{l}0.25 \\
(0.09-0.71)\end{array}$ & $\begin{array}{l}0.07 \\
(0.01-0.46)\end{array}$ & $\begin{array}{l}0.31 \\
(0.12-0.81)\end{array}$ & $\begin{array}{l}0.10 \\
(0.02-0.65)\end{array}$ & $\begin{array}{l}0.39 \\
(0.2-0.78)\end{array}$ & 0 \\
\hline
\end{tabular}

Table 6: Overall efficiency of SIS compared with TVS.

\begin{tabular}{|c|c|c|c|c|c|}
\hline \multirow[b]{2}{*}{ Study } & \multirow[b]{2}{*}{ Procedure } & \multirow[b]{2}{*}{ Sensitivity \% } & \multicolumn{3}{|c|}{ Predictive Value } \\
\hline & & & Specificity \% & PPV \% & NPV \% \\
\hline \multirow{2}{*}{ Ryu JA et al } & SIS & 95 & 83 & 95 & 83 \\
\hline & TVS & 79 & 46 & 83 & 39 \\
\hline \multirow{2}{*}{ Saidi et al } & SIS & 90.9 & 83.3 & 90.9 & 16.7 \\
\hline & TVS & 95.7. & 63.6 & 84.6 & 12.5 \\
\hline \multirow{2}{*}{ Reddy Rani P et al } & SIS & 82 & 95 & 81 & 93 \\
\hline & TVS & 65.5 & 88 & 68 & 90 \\
\hline \multirow{2}{*}{ Goyal et al } & SIS & 100 & 96.08 & 96.08 & 100 \\
\hline & TVS & 87.76 & 96.08 & 95.56 & 89.09 \\
\hline \multirow{2}{*}{ Present Study } & SIS & 92.86 & 89.65 & 86.67 & 94.54 \\
\hline & TVS & 71.43 & 67.7 & 54.35 & 81.48 \\
\hline
\end{tabular}

Heavy menstrual bleeding (menorrhagia) was the commonest symptom in $64 \%$ of the cases and the most common lesion was intramural myoma in $50 \%$ similar to the finding of Laughead et al. ${ }^{1}$ TVS failed to locate the exact site of myoma in $12 \%$ of the cases in our study. Hill in his study found that TVS was not able to determine the location of myoma in $10 \%$ the cases, whereas SIS helped to take exact measurement of myoma and also in determining the depth of penetration in to the myometrium. ${ }^{2}$

Present study showed that SIS has higher sensitivity 92.46 and specificity 89.65 when compared with TVS with sensitivity 71.43 and specificity 67.7. Similar findings were seen in the studies by Saidi et al (Table 6). ${ }^{5}$
De Kroon et al in a meta analysis reviewed 16 studies comprising 877 procedures to determine the diagnostic accuracy of SIS in perimenopausal women with AUB and comparing it to hysteroscopy with or without HPE or hysterectomy, found sensitivity of SIS for evaluating the uterine cavity was 0.95 and pooled specificity was 0.88 and the sonographic procedure was successful in $86.5 .^{4}$

Dueholm et al in their study of 105 patients found the sensitivity and specificity of saline infusion sonohysterography for detection of polyps were significantly higher than for transvaginal ultrasound alone (93 and 94 versus 75 and 76 percent for TVS) and were comparable to hysteroscopy. ${ }^{5}$ SIS is found to be more accurate than TVS to visualize the endometrial cavity Kazandi et al. ${ }^{6}$ TVS cannot distinguish endometrial hyperplasia from 
polyps as both can cause thickening of the endometrium, are hyperechoic and can contain cystic spaces whereas SIS can detect focal lesions from diffuse thickening.

SIS correlation with intraoperative hysterectomy findings and HPE for submucous myoma showed sensitivity of $100 \%$ and specificity of $100 \%$ with $0 \%$ positive and negative LR, whereas with TVS there was good correlation for intramural myoma but with sub mucous myoma sensitivity was $61.54 \%$ and specificity was $97.67 \%$ with a LR positive rate of $26.46 \%$ and negative rate of $0.39 \%$. All imaging techniques have a number of false results even in experienced hands. In the present study false positive and negative were higher in TVS than SIS which was due to large intramural myoma compressing the cavity, hemorrhagic debris, sessile polyps, and polyps arising from endocervix or when the inflated foley's bulb compresses these lesions. Ryu et al found $12 \%$ false negative and false positive cases in TVS which were due to small polyps of less than $5 \mathrm{~mm}$, synechia and chronic endometritis. ${ }^{7}$

Overall sensitivity, specificity, PPV and NPV of SIS in present study were as $92.86,89.65,86.67$ and 94.54 in comparison to that of TVS i.e.71.43, 67.7, 54.34 and 81.48 . These are comparable with the results observed by Reddi et al and Goyal et al (Table 6). ${ }^{8,9}$

One postmenopausal women $(1 \%)$ experienced severe pain in our study whereas in the study by Cicinelli et al $11 \%$ of the patients experienced severe pain. ${ }^{10}$ The pain due to distension of uterine cavity can be minimized if saline instillation is controlled and stopped as soon as the lesion is detected. There was no evidence of infection in our study. Chung et al in their review of 900 procedures of SIS observed infection rate of $0.6 \% .{ }^{11}$ Bonnamy et al found $1 \%$ infection rate and $1 \%$ pelvic pain. ${ }^{12}$

\section{CONCLUSION}

TVS is a simple, minimally invasive low-cost technique and it should be the first diagnostic method of choice in evaluating AUB. The appropriate clinical place for SIS is a second line diagnostic procedure in the evaluation of AUB if TVS findings are inconclusive.

It is highly sensitive and specific especially for diagnosing, submucous myoma, endometrial polyps and thickened endometrium. It is an alternative to hysteroscopy with the additional advantage of evaluating myometrial and adnexal pathology besides being less invasive and cost effective.

\section{Funding: No funding sources}

Conflict of interest: None declared

Ethical approval: The study was approved by the Institutional Ethics Committee

\section{REFERENCES}

1. Laughead MK, Stones LM. Clinical utility of saline solution infusion sonohysterography in a primary care obstetric-gynecologic practice. Am J Obstet Gynecol. 1997;176:1313-6.

2. Hill DA. Sonohysterography in the office: Instruments and technique. Contemp Obstet Gynecol. 1997;42:95110.

3. Saidi MH, Sadler RK, Theis VD. Comparison of sonography, sonohysterography and hysteroscopy for evaluation of abnormal uterine bleeding. J Ultrasound Med. 1997;16:587-91.

4. de Kroon CD, de Bock GH, Dieben SW. Saline contrast hystero-sonography in abnormal uterine bleeding: a systematic review and meta-analysis. BJOG. 2003:110:938-47.

5. Dueholm M, Forman A, Jensen ML, Laursen H, Kracht P. Transvaginal sonography combined with saline contrast sonohysterography in evaluating the uterine cavity in premenopausal patients with abnormal uterine bleeding. Ultrasound Obstet Gynecol. 2001;18(1):54-61.

6. Kazandi M, Akşehirli S, Cirpan T, Akercan F, Transvaginal sonography combined with saline contrast sonohysterography to evaluate the uterine cavity in patients with abnormal uterine bleeding and postmenopausal endometrium more than $5 \mathrm{~mm}$. Eur J Gynaecol Oncol. 2003;24(2):185-90.

7. Ryu JA, Kim B, Lee J. Comparison of transvaginal ultrasonography with hysterosonography as a screening method in patients with abnormal uterine bleeding. Korean J Radiol. 2004:5:39-46.

8. Rani RP, Lakshmikantha G. Transvaginal Sonography (TVS) and Saline Infusion Sonohysterography (SIS) in the evaluation of Abnormal Uterine Bleeding (AUB). J Obstet Gynecol India. 2010;60(6):511-5.

9. Goyal AS, Chaudhari SJ, Shrivastava AR, Verma RN. Comparison of transvaginal sonography and saline infusion sonohysterography for the diagnosis of causes of abnormal uterine bleeding: a diagnostic accuracy study. IJRCOG. 2016;5:1566-70.

10. Cicinelli E, Romano F, Anastasio PS. Transabdominal sonohysterography transvaginal sonography and hysteroscopy in the evaluation of submucous myomas. Obstet Gynecol. 1995;85:42-7.

11. Chung PH, Parsons AK. A practical guide to the using saline infusion sonohysterography. Contemp Obstet Gynecol. 1997;42:21-34.

12. Bonnamy L, Marret H, Perrotin F. Sonohysterography a prospective survey of results and complications in 81 patients. Eur $\mathbf{J}$ Obstet Gynecol Reprod Biol. 2002:102:42-7.

Cite this article as: Gupta N, Singh G, Jain B, Garg

$\mathrm{S}$. Role of saline infusion sonography in evaluation of abnormal uterine bleeding. Int J Reprod Contracept Obstet Gynecol 2018;7:1130-4. 